\title{
Evaluating Service Quality in Official Vehicle Management
}

\author{
Ji-Chuan Quan, Bing Wang ${ }^{*}$, Yong Liu \\ PLA University of Science and Technology, Nanjing, China \\ Science and Technology on Information Transmission and Dissemination in Communication \\ Networks Laboratory, Shijiazhuang, China \\ qjch_cn@sina.com \\ ${ }^{*}$ Corresponding author
}

Keywords: SERVQUAL model, Service quality, Evaluation Index, Official vehicle management.

\begin{abstract}
The SERVQUAL model generated from service industries is an effective evaluation model about service quality in the business field. But its application in other fields is to be researched and validated. The development, concept and characteristics of SERVQUAL model are analyzed. According to service characteristics of official vehicle management, the model is improved. On the basis of SERVQUAL measurements of PZB, nine indexes are deleted, five indexes are increased, two indexes are merged and the descriptions are optimized. Then, a kind of evaluation model for service quality of the official vehicle management system is promoted. Finally, the evaluation process is discussed. It shows that the improved model can be used to evaluate the service quality in official vehicle management effectively.
\end{abstract}

\section{Introduction}

Evaluation on service quality is a common work in many fields. It is unavoidable that almost all the evaluation involves the user's cognition and feeling to the service, either in evaluating the service of people in common service fields or evaluating the information service in information industry fields. So, it is significant for these fields to research evaluation model on service quality that can reflect the user's perceptions.

From 1980's, there have been many influential theories researching service quality evaluation. In 1982, Gronroos from north Europe brought forward customer's perception model for service quality ${ }^{[1]}$, which established the basis of service quality evaluation system. In 1985, American researchers Parasuraman, Zeithaml and Berry (PZB) promoted a gap model for service quality ${ }^{[2]}$. That model had advanced the development of the service quality evaluation system. These models have been applied in many fields. And there are also their variations, such as relation quality model ${ }^{[3]}$, Lovelock's service quality model ${ }^{[4]}$, Bolton and Drew's service quality model ${ }^{[5]}$, etc.

In recent years, PZB's SERVQUAL model was widely used to evaluate service quality of business organizations and common departments. There are differences for the same model to be used in different fields. According to his researching results, Orwig pointed out that SERVQUAL model must be revised based on characteristics of a certain field to suit that field better ${ }^{[6]}$.

We try to evaluate the service quality of official vehicle management process from viewpoint of user's perception. Our quality evaluation model is the further extension of PZB's SERVQUAL model in official vehicle management field. It is also an attempt to evaluate service quality in common management fields.

\section{SERVQUAL Model}

\section{Concept and Characteristics}

The core of SERVQUAL model is service quality gap model. The cognition about user's expectations is the precondition of high quality. The key of high quality is to exceed the user's expectations, shown in Fig. 1. Service quality is the function of service gap between expectations and perceptions. So, we may 
measure service quality by measuring the gaps. Bigger gaps mean more dissatisfaction to the service quality.

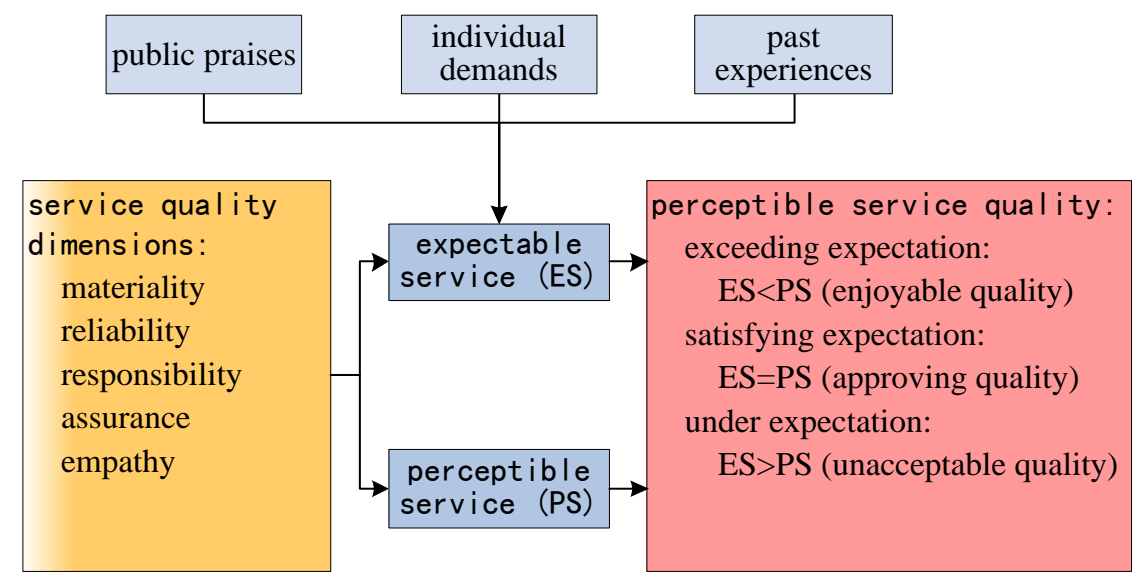

Fig. 1 The SERVQUAL model

The gaps between user's perceptions and expectations may be considered as the basis of evaluating service quality. Here, user's perception means the user's experience in the process of using service and user's cognition and feeling about service after using. The results of user's perception have relation to the using process and the expectation before using. The service should satisfy the user's demands in a certain extent.

We can explain the SERVQUAL model from subjective and objective aspects. From the subjective aspect, user's perception and subjective evaluation uncover the goodness or badness of the service quality. And the user has some expectations to the service quality. If the providing service can't reach the user's expectations, his perceptions or evaluation will be low, and vice versa. So, information user usually evaluates the service quality according to his expectations on service level. From the objective aspect, in the process of service running, there must be many measurable performance factors or quality parameters. These parameters may bring users evident sensible cognitions. So, users will receive different experiences from different service factors when using service.

In the practice of applying SERVQUAL model, the service quality gap model is usually adopted. It is shown in Fig. 2.

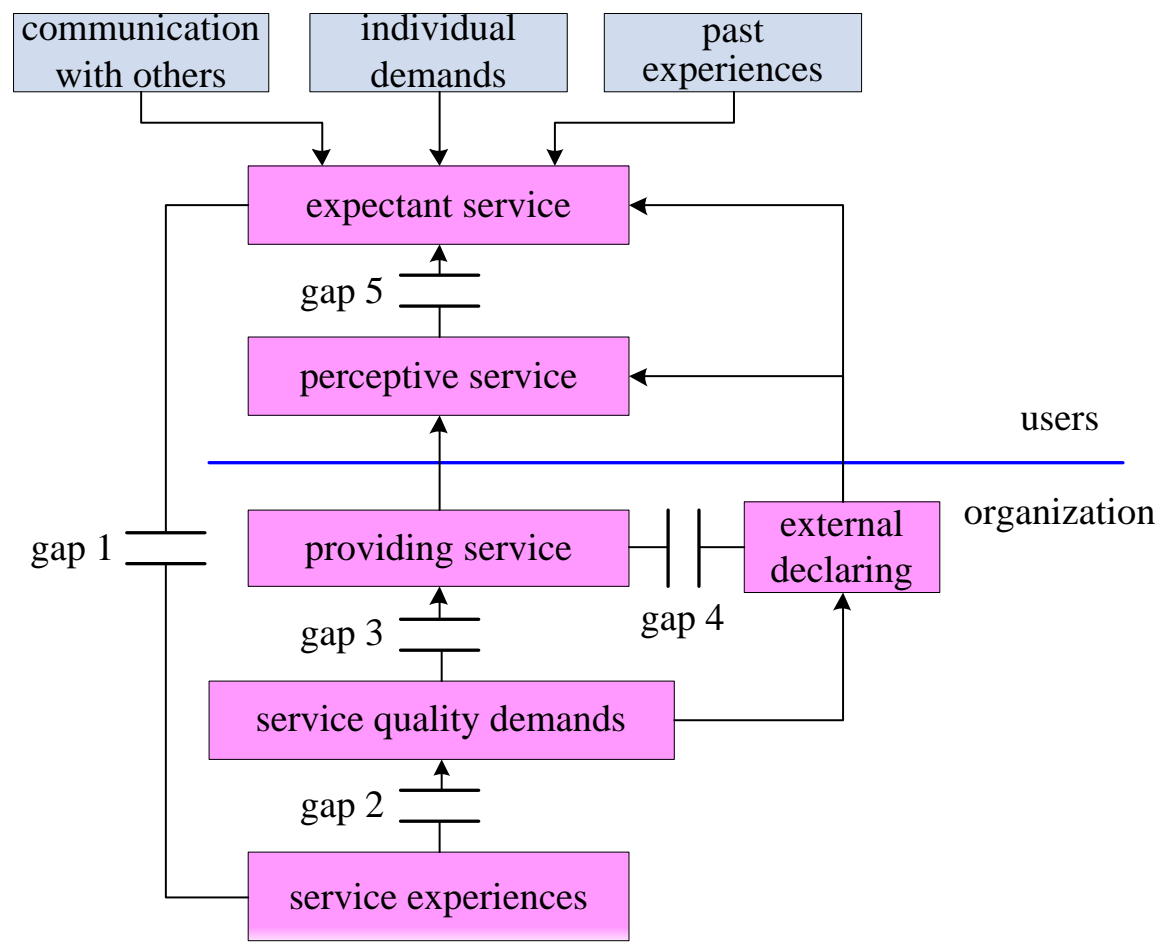

Fig. 2 The service quality gap model 
In Fig. 2, there are five gaps between users and service. The $5^{\text {th }}$ gap is the synthetic effects of the other gaps, that is the gap between user's expectant service and user's perceptive service. We may measure the above gaps through proper evaluation indexes to evaluate the service quality.

\section{Evaluation Indexes System of SERVQUAL Model}

The evaluation indexes system of SERVQUAL model is used to measure the gaps quantitatively. It is divided into five dimensions including materiality, reliability, responsibility, assurance and empathy. Those dimensions have 22 indexes, shown in Table 1.

Tab. 1 Evaluation indexes system of SERVQUAL model

\begin{tabular}{c|l}
\hline dimension & \multicolumn{1}{c}{ index } \\
\hline materiality & $\begin{array}{l}\text { 1. have modern service establishments } \\
\text { 2. service establishments have attraction } \\
\text { 3. the staffs have tidy service and appearance } \\
\text { 4. the establishments suit for the service }\end{array}$ \\
\hline \multirow{5}{*}{ reliability } & $\begin{array}{l}\text { 5. promising things can be accomplished in time } \\
\text { 6. care and help customers when they encounter problems } \\
\text { 7. the company is reliable } \\
\text { 8. provide the promising service exactly } \\
\text { 9. record relative service correctly }\end{array}$ \\
\hline \multirow{5}{*}{ responsibility } & $\begin{array}{l}\text { 11. you can't expect them to tell customers the exact time of providing serivce } \\
\text { 12. the stuffs would not always help customers } \\
\text { 13. the stuffs can't provide service immediately to the customers because of too } \\
\text { busy }\end{array}$ \\
\hline empathy & $\begin{array}{l}\text { 14. the stuffs can be trusted } \\
\text { 15. the customers will feel reassurance when they use service } \\
\text { 16. the stuffs are polite } \\
\text { 17. the stuffs can obtain proper support from the company to provide better serivce }\end{array}$ \\
$\begin{array}{l}\text { 18. the company will not provide individual service to different customers } \\
\text { 19. the stuffs will not give customers individual care } \\
\text { 20. you can't expect the stuffs to understand the customers' demands } \\
\text { 21. the company will not consider the customers' benefits preferentially } \\
\text { 22. the service time provided can't suit all the demands of the customers }\end{array}$ \\
\hline
\end{tabular}

\section{Evaluating Service Quality of Official Vehicle Management}

Literature [7] shows that SERVQUAL model can be used in nonprofit organizations after revised. For example, literature [8] applied the model to research information technology service quality through merging assurance and empathy dimension to a whole empathy dimension and increasing the security dimension. So we try to improve the model to suit the official vehicle management fields. The indexes system must be changed according to characteristics of official vehicle management.

\section{Evaluation Indexes System}

Now in China, many organizations especially Governments and military departments have carried on official vehicle reforming. That is all the vehicles in an organization are centralized and managed by a vehicle service center to save resources. A user, for example a clerk, is going to do some work in a different place. He needs to apply a vehicle by phone or through the intranet. After receiving the application, the vehicle service center should schedule an idle vehicle to ensure the user arriving to the destination in time. It is important to know the service quality of management in the above process. It involves the vehicle, the driver, the scheduling system and the service process. Basing on the SERVQUAL indexes system, we deleted 9 indexes, added 5 indexes and merged 2 indexes to construct an indexes system with 17 indexes. Our indexes system is shown in Table 2. 
Tab. 2 Evaluation indexes system of official vehicle service quality

\begin{tabular}{c|l}
\hline dimension & \multicolumn{1}{c}{ index } \\
\hline \multirow{3}{*}{ materiality } & $\begin{array}{l}\text { 1. scheduling mode is advanced and diversiform } \\
\text { 2. scheduling mode is simple and convenient } \\
\text { 3. the drivers are uniformed and tidy }\end{array}$ \\
\hline \multirow{2}{*}{ reliability } & $\begin{array}{l}\text { 4. scheduling system is robust and stable } \\
\text { 5. the vehicles are scheduled exactly } \\
\text { 6. record relative service correctly }\end{array}$ \\
\hline responsibilit & $\begin{array}{l}\text { 7. the vehicle application is accepted in time } \\
\text { 8. the feedback of scheduling information is timely } \\
\text { 9. the feedback of complaint is timely }\end{array}$ \\
\hline \multirow{2}{\text{assurance}}{} & $\begin{array}{l}\text { 10. the drivers can be trusted } \\
\text { 11. the vehicles can be trusted } \\
\text { 12. the drivers are polite } \\
\text { 13. the quantity of vehicles and drivers is enough } \\
\text { 14. the drivers are supported well by the organization to provide better serivce }\end{array}$ \\
\hline & $\begin{array}{l}\text { 15. provide individual service to different tasks } \\
\text { 16. the path for complaining is expedite } \\
\text { 17. there are always vehicles and drivers for emergent tasks }\end{array}$ \\
\hline
\end{tabular}

\section{Evaluation Dimensions}

Materiality. The service establishments are vehicle scheduling system and official vehicles. The scheduling system should be convenient and easily used. And the users need flexible scheduling modes. The drivers should provide high quality service. In a way, from their clothes and spirits, you can feel a certain quality.

Reliability. The faults of the scheduling system will affect the user's application. So the system needs to be stable. The correctness of scheduling represents the reliability of the vehicle management process which includes applying, scheduling, dispatching and using. In addition, we must record the scheduling service and user's complaint to know the service states and to prove the quality.

Responsibility. Timely acceptance and feedback to user's application are the precondition of correctly scheduling. So the timeliness of the above two reflects the responsibility of the scheduling process. Furthermore, the feedback to user's complaint also reflects the responsibility.

Assurance. The assurance dimension mainly measures the vehicle using process, including evaluation indexes about drivers and vehicles. Firstly, the drivers should be reliable and polite, which will bring comfort to the user. Secondly, the drivers and vehicles should be enough to guarantee successful service. Thirdly, the performance and appearance of the vehicles should be very well. Finally, the organization should support its drivers and vehicles. So they will provide better service.

Empathy. Providing individual service expresses good care to the users ${ }^{[9]}$. In addition, accepting the user's feedback and complaint will be considered warmhearted. So, the path for feedback should be straightforward. And the organization is expected to deal with the complaint and answer the users quickly.

\section{Evaluation Process}

If we use the above indexes system to evaluate the service quality, we must setup the weight for every index. The weight represents the relative importance of different indexes to the whole service quality. Generally, we use the analytical hierarchy process (AHP method) to compute the index weights. That method combines the advantages of qualitative analysis and quantitative analysis. It is used to deal with decision problems and decomposes the problem into several layers. Each layer includes its indexes. Through judging matrix and consistency test, the AHP method transforms people's subjective judgment to quantitative weight values.

Following is the evaluation process:

Step 1: compute the weights of each dimension and carry on consistency test. 
Invite vehicle managers, schedulers, drivers and users to give judgment about the relative importance of the five dimensions. Through comparison of every two dimensions, we will obtain the judging matrix. Then, compute the relative weights by geometric mean method. Finally carry on consistency test to verify the consistency of the judging matrix.

Step 2: compute the relative weights of every index in each dimension.

Compute the weights of the indexes contained in each dimension. The method is similar with step 1 . So, we must compute five judging matrixes for five dimensions.

Step 3: compute the synthetic weights.

In the last two steps, we have obtained the dimension weight and the index weight. Multiply the two weights, we will compute the synthetic weights of the indexes. These weights represent the contribution of every index to the whole service quality.

Step 4: carry on questionnaire survey and collect the index values.

Design evaluation tables and carry on questionnaire survey to the stuffs of the organization. Collect evaluation data and stat the index values.

Step 5: evaluate the service quality synthetically.

Use weighted sum method. That is, multiply the index weights in step 3 and the index values in step 4 correspondingly. And sum the above products into one value. That is the synthetic evaluation result of the service quality.

The AHP method is a very popular evaluation method. So, we didn't give detailed descriptions for the above steps. Interesting readers may refer to literature [10] or other references.

\section{Summary}

SERVQUAL model is a classical model reflecting user's perceptions in evaluation process. Its concept, development and indexes system are discussed. According to the characteristics of official vehicle management, we improved the model and indexes system. There are 17 evaluation indexes used to evaluate the service quality of official vehicle management process. The AHP method is used in the evaluation process. The next work is analyzing the survey data and optimizing the indexes system to enhance its practicability.

\section{Acknowledgement}

This research was financially supported by Science and Technology on Information Transmission and Dissemination in Communication Networks Laboratory.

\section{References}

[1] C. Gronroos, A service quality model and its marketing implications, European Journal of marketing, 1984, 18(4), pp. 36-44.

[2] A. Parasuraman, V. Zeithaml, L. Berry, A conceptual model of service quality and its implications for future research, The Journal of Marketing, 1985, pp. 41-50.

[3] Veronica Liljander, Comparison Standards in Perceived Service Quality, Helsingfors, 1996.

[4] Christopher Lovelock, Product Plus: How Product + Service $=$ Competitive Advantage, McGraw-Hill, 1994.

[5] R. N. Bolton, J. H. Drew, A multistage model of customers' assessments of service quality and value, Journal of Customer Research, 1991, 17(4), pp. 375-384.

[6] R. A. Orwig, J. Pearson, D. Cochran, An empirical investigation into the validity of SERVQUAL in the public sector, PAQ Spring, 1997, 21(1), pp. 54-66. 
[7] SHI Guo-hong, WANG Xiao-yan, YUE Jiang-jun, The study of the non-profit organization service quality evaluation model based on SERVQUAL, East China Economic Management, 2011, pp. 147-150.

[8] JIA Hong-long, The study of quality evaluation model for information technology service based on SERVQUAL, Information Technology and Standardization, 2010.03, pp. 52-55.

[9] M. Donnelly, M. S. Edward, Assessing service quality and its link with value for money in a UK local authority's housing repairs service using the SERVQUAL approach, Total Quality Management, 1999, pp. 498-506.

[10]ZENG Bao-chang, XUE Shu-mei, REN Lian-zhi, Study of analytic hierarchy decision method and its application, Journal of Inner Mongolia University of Technology (Social Sciences Edition), 1998, pp. 66-74. 